\title{
FAMILY PHYSICIANS' OPINION: A SURVEY ON POSSIBLE MEASURES FOR IMPROVING HEALTHCARE IN ROMANIA
}

\section{Chirila Sergiu', Severin Beatrice'}

${ }^{1}$ Faculty of Medicine, University "Ovidius" of Constanta

Sergiu Chirila

Faculty of Medicine, Univeristy ,Ovidius” of Constanta, Universitatii Alee No. 1, Campus B, Constanta, Romania email:sergiu.chirila@univ-ovidius.ro phone: +40721332068

\begin{abstract}
Primary health care (PHC) represents one of the most important parts of any health system, and consists of first-contact medical services (preventive, curative and rehabilitation) for the patients. Our study analyses the family physicians' opinions related to a series of measures that could improve Romania's healthcare system through an online survey.

We identified three components, first one related to control over spendings, increase of medicine market efficiency and transparency in using public funds, second one related to standardization of care processes, accreditation, implementation of guidelines and control over utilization of specialty services and component number three related to type of insurance houses, with competition among them, better decentralization and integrated provision of medical services.

The conclusions of the survey emphasize the fac that primary care health is affected by sub optimal financing, with a need of better support for its development through investments in health promotion, services integragion and human resources as means of increasing general health status of the population.
\end{abstract}

Keywords: family physicians, healthcare system, actions, resources

\section{Introduction}

Primary health care (PHC) represents one of the most important parts of any health system, and consists of first-contact medical services (preventive, curative and rehabilitation) for the patients (1). To sustain this idea, data from countries in which PHC is well developed shows that the health of the population is within optimal parameters. In Romania, according to the current legislation, primary health care is conducted through family medicine. Nevertheless, this part of the medicine is not very attractive for new generations, and the ones that are already working as family doctors have many complaints related especially to the financing and the volume of administrative activities.

Thus, our study analyses the family physicians' opinions related to a series of measures that could improve Romania's healthcare system.

\section{Material and method}

The study was conducted on 93 family physicians from Romania that responded to an electronic questionnaire, created by using Google Forms. Participants had a good representation at the country level, with respondents from all areas of the country. The answers were collected in a period of one week at the end of May 2017. 
The questionnaire, which consisted of 17 items specific for the topic, was disseminated through national discussion groups were family physicians communicate, through the groups of local leaders of the associations and other groups frequented by family physicians.

The collected data was analyzed in IBM SPSS Statistics, using principal component analysis.

\section{Results}

The answers to the questions contained in the questionnaire, relevant to the topic of the article, can be consulted in Table 1 .

In figure 1 we graphically represent the results of the questionnaire in decreasing order of the percentages of answers that consider the specific measure as being necessary, adequate for the Romanian health system.

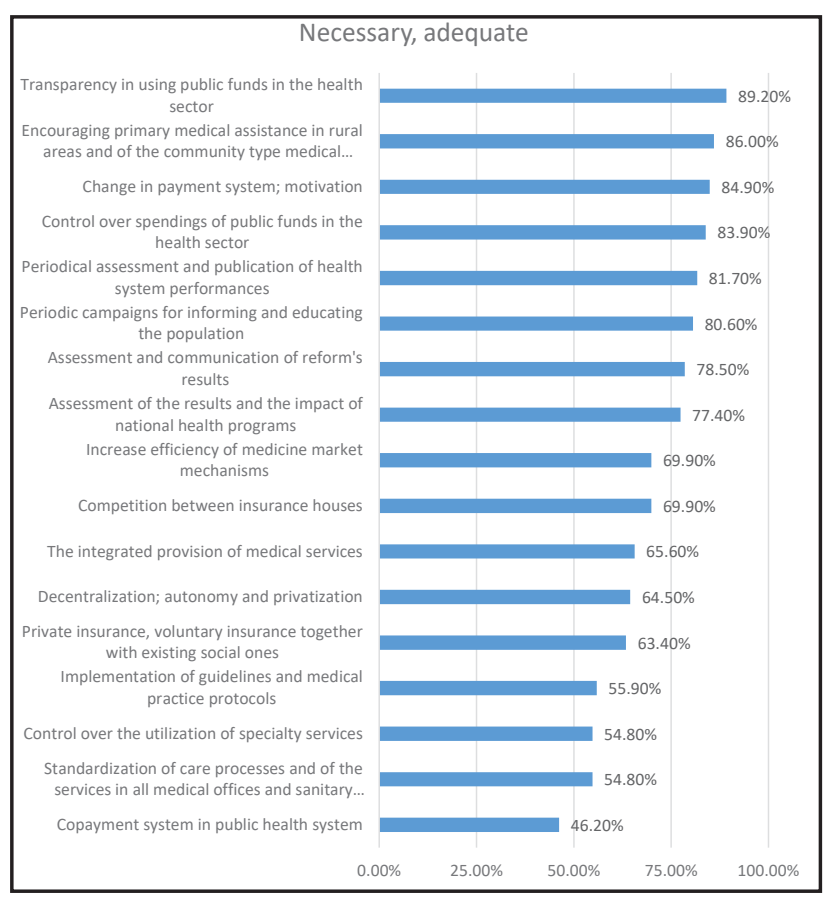

Figure 1 Percentage of "necessary, adequate" answer for different measures proposed for the health system

Table 1 Opinion about different measures for Romania's health system

\begin{tabular}{|c|c|c|c|c|c|c|c|c|}
\hline & \multicolumn{2}{|c|}{ Inadequate } & \multicolumn{2}{|c|}{ Less adequate } & \multicolumn{2}{|c|}{$\begin{array}{c}\text { Relatively } \\
\text { adequate }\end{array}$} & \multicolumn{2}{|c|}{$\begin{array}{c}\text { Necessary } \\
\text { adequate }\end{array}$} \\
\hline & Count & $\%$ & Count & $\%$ & Count & $\%$ & Count & $\%$ \\
\hline Copayment system in public health system & 9 & $9.7 \%$ & 19 & $20.4 \%$ & 22 & $23.7 \%$ & 43 & $46.2 \%$ \\
\hline $\begin{array}{l}\text { Private insurance, voluntary insurance together with } \\
\text { existing social ones }\end{array}$ & 4 & $4.3 \%$ & 12 & $12.9 \%$ & 18 & $19.4 \%$ & 59 & $63.4 \%$ \\
\hline Competition between insurance houses & 6 & $6.5 \%$ & 9 & $9.7 \%$ & 13 & $14.0 \%$ & 65 & $69.9 \%$ \\
\hline $\begin{array}{l}\text { Implementation of guidelines and medical practice } \\
\text { protocols }\end{array}$ & 3 & $3.2 \%$ & 8 & $8.6 \%$ & 30 & $32.3 \%$ & 52 & $55.9 \%$ \\
\hline $\begin{array}{l}\text { Standardization of care processes and of the } \\
\text { services in all medical offices and sanitary } \\
\text { institutions; accreditation }\end{array}$ & 2 & $2.2 \%$ & 7 & $7.5 \%$ & 33 & $35.5 \%$ & 51 & $54.8 \%$ \\
\hline of snecialty services & 0 & $.0 \%$ & 12 & $12.9 \%$ & 30 & $32.3 \%$ & 51 & $54.8 \%$ \\
\hline $\begin{array}{l}\text { Encouraging primary medical assistance in rural } \\
\text { areas and of the community type medical services, } \\
\text { adapted to the existing needs }\end{array}$ & 0 & $0.0 \%$ & 2 & $2.2 \%$ & 11 & $11.8 \%$ & 80 & $86.0 \%$ \\
\hline The integrated provision of medical services & 0 & $0.0 \%$ & 4 & $4.3 \%$ & 28 & $30.1 \%$ & 61 & $65.6 \%$ \\
\hline Decentralization; autonomy and privatization & 2 & $2.2 \%$ & 10 & $10.8 \%$ & 21 & $22.6 \%$ & 60 & $64.5 \%$ \\
\hline $\begin{array}{l}\text { Transparency in using public funds in the health } \\
\text { sector }\end{array}$ & 0 & $0.0 \%$ & 1 & $1.1 \%$ & 9 & $9.7 \%$ & 83 & $89.2 \%$ \\
\hline Change in payment system; motivation & 0 & $0.0 \%$ & 1 & $1.1 \%$ & 13 & $14.0 \%$ & 79 & $84.9 \%$ \\
\hline $\begin{array}{l}\text { Control over spendings of public funds in the health } \\
\text { sector }\end{array}$ & 0 & $0.0 \%$ & 3 & $3.2 \%$ & 12 & $12.9 \%$ & 78 & $83.9 \%$ \\
\hline cy of medicine market mechanisms & 0 & $0.0 \%$ & 5 & $5.4 \%$ & 23 & $24.7 \%$ & 65 & $69.9 \%$ \\
\hline $\begin{array}{l}\text { Periodic campaigns for informing and educating the } \\
\text { population }\end{array}$ & 1 & $1.1 \%$ & 2 & $2.2 \%$ & 15 & $16.1 \%$ & 75 & $80.6 \%$ \\
\hline $\begin{array}{l}\text { Assessment of the results and the impact of national } \\
\text { health programs }\end{array}$ & 1 & $1.1 \%$ & 4 & $4.3 \%$ & 16 & $17.2 \%$ & 72 & $77.4 \%$ \\
\hline Assessment and communication of reform's results & 1 & $1.1 \%$ & 3 & $3.2 \%$ & 16 & $17.2 \%$ & 73 & $78.5 \%$ \\
\hline $\begin{array}{l}\text { Periodical assessment and publication of health } \\
\text { system performances }\end{array}$ & 1 & $1.1 \%$ & 3 & $3.2 \%$ & 13 & $14.0 \%$ & 76 & $81.7 \%$ \\
\hline
\end{tabular}


A principal component analysis (PCA) was run on the 17-question questionnaire. The suitability of PCA was assessed prior to analysis. Inspection of the correlation matrix showed that all variables, except "Copayment system in public health" item had at least one correlation coefficient greater than 0.3 . Therefore, this item was excluded from the PCA analysis. The overall Kaiser-Meyer-Olkin (KMO) measure was 0.815 with individual KMO measures with the lowest value 0.676 , classifications of 'mediocre', 'middling' and 'meritorious according to Kaiser's classification. Bartlett's test of sphericity was statistically significant $(\mathrm{p}<0.0005)$, indicating that the data was likely factorizable.

PCA revealed three components that had eigenvalues greater than one and which explained $37.9 \%, 12.54 \%$ and $9.39 \%$ of the total variance, respectively. Visual inspection of the scree plot (Figure 2) indicated that three components should be retained. In addition, a three-component solution met the interpretability criterion. As such, three components were retained.

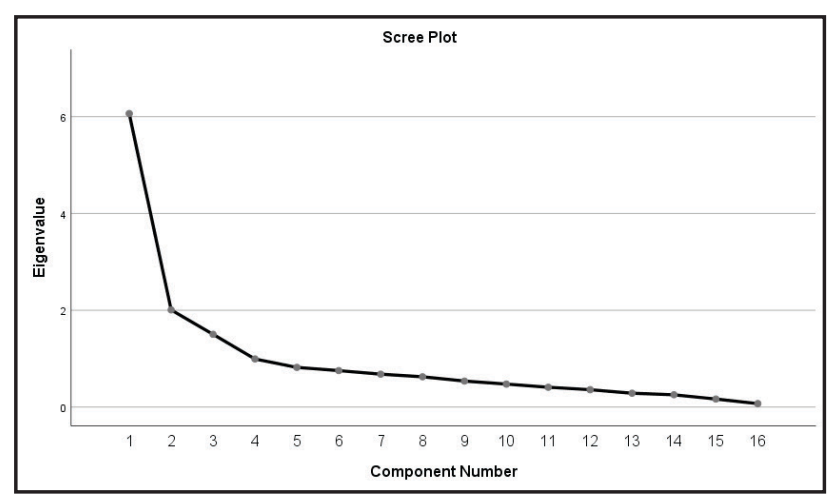

Figure 2 Scree plot

The three-component solution explained $59.84 \%$ of the total variance. A Varimax orthogonal rotation was employed to aid interpretability. The rotated solution exhibited a simple structure. The interpretation of the data was consistent with the type of interventions it was designed to measure, with strong loadings on most of the items on Component 1 (Table 2). Measures related to control over spending, increase of medicine market efficiency and transparency using public funds had a strong loading on Component 2 also. Intervention

Table 2 Rotated Structure Matrix for PCA with Varimax Rotation of a Three-Component Questionnaire

\begin{tabular}{|c|c|c|c|c|}
\hline \multirow[b]{2}{*}{ Items } & \multicolumn{4}{|c|}{ Rotated Component Coefficients } \\
\hline & $\begin{array}{c}\text { Component } \\
1\end{array}$ & \begin{tabular}{|c|} 
Component \\
2
\end{tabular} & \begin{tabular}{|c|} 
Component \\
3
\end{tabular} & Communalities \\
\hline Assessment and communication of reform's results & 0.879 & 0.214 & 0.035 & 0.819 \\
\hline $\begin{array}{l}\text { Assessment of the results and the impact of national health } \\
\text { programs }\end{array}$ & 0.852 & 0.212 & 0.015 & 0.771 \\
\hline $\begin{array}{l}\text { Periodical assessment and publication of health system } \\
\text { performances }\end{array}$ & 0.800 & 0.164 & -0.002 & 0.668 \\
\hline Periodic campaigns for informing and educating the population & 0.717 & -0.008 & 0.166 & 0.542 \\
\hline Control over spendings of public funds in the health sector & 0.655 & 0.465 & 0.055 & 0.648 \\
\hline Increase efficiency of medicine market mechanisms & 0.652 & 0.387 & 0.029 & 0.576 \\
\hline Transparency in using public funds in the health sector & 0.648 & 0.311 & 0.292 & 0.602 \\
\hline Change in payment system; motivation & 0.643 & -0.154 & 0.261 & 0.506 \\
\hline $\begin{array}{l}\text { Encouraging primary medical assistance in rural areas and of the } \\
\text { community type medical services, adapted to the existing needs }\end{array}$ & 0.443 & 0.042 & 0.385 & 0.346 \\
\hline $\begin{array}{l}\text { Standardization of care processes and of the services in all } \\
\text { medical offices and sanitary institutions; accreditation }\end{array}$ & 0.146 & 0.816 & 0.081 & 0.694 \\
\hline Implementation of guidelines and medical practice protocols & 0.001 & 0.786 & 0.249 & 0.681 \\
\hline Control over the utilization of specialty services & 0.247 & 0.617 & 0.099 & 0.452 \\
\hline $\begin{array}{l}\text { Private insurance, voluntary insurance together with existing } \\
\text { social ones }\end{array}$ & -0.047 & 0.125 & 0.837 & 0.719 \\
\hline Competition between insurance houses & -0.045 & 0.164 & 0.774 & 0.628 \\
\hline Decentralization; autonomy and privatization & 0.331 & 0.176 & 0.597 & 0.497 \\
\hline The integrated provision of medical services & 0.398 & 0.019 & 0.516 & 0.425 \\
\hline \multicolumn{5}{|l|}{ Extraction Method: Principal Component Analysis. } \\
\hline 3 comnonents oytrocted & & & & \\
\hline
\end{tabular}


related to standardization of care processes, accreditation, implementation of guidelines and control overutilization of specialty services were very strong on Component 2. Component 3 loadings were related to additional types of insurance houses, with competition among them, better decentralization and integrated provision of medical services.

\section{Discussions}

Even though two-thirds of the family physicians consider private insurance houses and voluntary ones as being necessary or adequate for the Romanian health system, these are poorly represented, with a very small number of people having one, in comparison to the situation in other European or non-European countries.

Private insurance houses are important for the health systems like the ones from United States, Holland, France, Germany, Canada or Switzerland. In Romania, in the later years an increase in the number of people that have private insurances was observed, but these are well below the European Union average. Probably one of the reasons is related to economic status, but also because of the legislation.

Another key element for the Romanian health system is the access of the population to primary health services. According to the data published by the Organisation for Economic Cooperation and Development (OECD) in 2014, only $86 \%$ of the country's population had access to medical services within the public social insurance system (2). The situation was the same in 2015, but in 2017 the percentage saw an increase, but stayed below $90 \%$ (3).

Reported to the environment, most of the problems exist in the rural areas, where onequarter of the population does not have access to these services. Geographical and economic aspects are the most important factors (2). In the urban area, population without health services access is less than $6 \%$. Considering this situation, most of the family physicians that participated in the study considered that support for primary health care in rural area and of the community type medical services are necessary.

The authorities are considering the increase of financing of the health system and the revision of medical services, as possible solutions for some of the issues discussed above, but the specialists consider that this will not be solved in the near future.

On the other hand, the funds, which are not sufficient, are not used efficiently, either. That is why approximately $90 \%$ of the respondents consider that the funds for public health should be used transparently. A study published in 2017 by OECD and the European Observatory on Health Systems and Policies confirms the importance of decision-making transparency for a good functioning of the Romanian health system (3).

The need for an integrated approach of health services is another aspect emphasized by most family physicians, as primary health care does not have functional relationships with the other medical departments and, eventually, the patient is the one to suffer due to the lack of continuous care.

Of course, we should not ignore a major element of any healthcare system: prevention. This involves, on the one hand, educating the population towards a healthy lifestyle which includes food, water consumption, physical exercise and resting and, on the other hand, informing the population with regard to the medical services (immunization, screening tests etc), which can lead to a lower occurrence of various pathologies or to their early identification.

Although more than $80 \%$ of the family physicians included in the study claim the need to inform the population about these aspects, statistics show a very low degree of prevention, not only in our country, but in others, as well. For example, only $3 \%$ of the healthcare income was assigned for prevention, in 2017, in Europe. In Romania, the education for health is insufficient in family physicians' offices, as doctors have too many administrative responsibilities; there is virtually no education for health in schools and high schools, the vaccination rate is lower than the one in previous years, and the screening programs have not achieved the intended level. For example, the 2014 reports highlight the fact that, among women, only $27 \%$ of the target population managed to perform a test for cervical cancer within three years, while for breast cancer the test was performed on less than $7 \%$ of the target population within two years (3). 
Currently, in Romania, we are trying to improve the health of the population by means of a series of actions included in the National Health Strategy, which was started in 2014 and will end in 2020 (4). Even so, specialists claim that there are some population groups without access to health education programs, and the impact of these actions on the state of health cannot be accurately estimated.

\section{Conclusions}

The Romanian healthcare system has been underfunded for many years, and this affects the primary health care. The support and development of the family medicine could better cover the needs of this field, also having a positive subsequent influence on the hospital activity, especially because, at present, Romania has a high rate of hospitalization, compared with other European countries.

Human resources, health promotion and the integration of healthcare services are areas where more investment should be made.

\section{Acknowledgments}

We would like to show our gratitude to the family physicians that completed the survey.

\section{References}

1. Zanoschi G. Sănătate publică şi management sanitar. Iași: Editura DAN; 2003; p.205-220.

2. OECD, Union E. Health at a Glance: Europe 2016.

3. OECD, Systems EOoH, Policies. Romania: Profilul Sănătății în 2017.

4. Ministerul Sănătății, Strategia Nationala de sanatate 2014-2020, [Available from: http:// www.ms.ro/strategia-nationala-desanatate-2014-2020/. 